\section{El Mar Caribe en la vida y la obra de Alejo Carpentier

\author{
ALEXIS MÁRQUEZ RODRÍGUEZ
} \\ Miembro de Número de la Academia Venezolana de la Lengua}

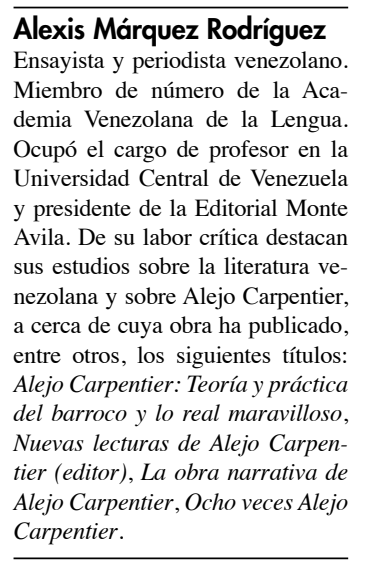

Alexis Márquez Rodríguez

Ensayista y periodista venezolano. demia Venezolana de la Lengua. Ocupó el cargo de profesor en la Universidad Central de Venezuela y presidente de la Editorial Monte nezolana y sobre Alejo Carpentier. a cerca de cuya obra ha publicado, entre otros, los siguientes títulos: Alejo Carpentier: Teoría y práctica del barroco y lo real maravilloso, Nuevas lecturas de Alejo Carpen(editor), La obra narrativa de Carpentier.

\title{
RESUMEN
}

La presencia del Mar Caribe en la vida y la obra de Alejo Carpentier es determinante en muchos sentidos. De hecho, el Caribe está presente en toda su obra narrativa, unas veces de modo directo, otras a través de referencias muy concretas e importantes. Puede decirse, en general, que el Mar Caribe o de las Antillas es un referente fundamental de todos sus cuentos y novelas. Por otra parte, también desde un punto de vista teórico ese mar tuvo mucha importancia en el pensamiento de Carpentier. El solo hecho de ser un insular tuvo en él, desde muy joven, un significado muy especial. Tanto dentro del ámbito geográfico, como del histórico y cultural, su Cuba nativa se perfiló en su conciencia como una realidad que no puede ser entendida ni valorada, si no se la considera en relación inmediata con el Caribe. Así, el artículo analiza la representación del Mar Caribe en algunos pasajes de sus obras principales, como Ecue-Yamba-O o El siglo de las luces.

Palabras clave: Carpentier, narrativa, Mar Caribe, Cuba.

\section{ABSTRACT}

The presence of the Caribbean Sea in the life and work of Alejo Carpentier is crucial in many respects. In fact, the Caribbean is present across his narrative, sometimes directly; other times, through very concrete and important references. It can be said, in general, that the Caribbean Sea or the Antilles is a fundamental referent in all his short-stories and novels. On the other hand, from a theoretical point of view, that sea was very important in Carpentier's thought. The mere fact of his own insularity, had on Carpentier, from a very young age, a very special meaning. Both in the geographical realm as well as in the historical and cultural ones, his native Cuba came to be on his conscience like a reality that could be neither comprehended nor valued, unless Cuba was not considered tightly linked to the Caribbean. Thus, this article analyzes the representation of the Caribbean Sea in some passages of Carpentier's main works, such as EcueYamba-O and El siglo de las luces.

Keywords: Carpentier, narrative, Caribbean Sea, Cuba.

\section{I}

La presencia del Mar Caribe en la vida y la obra de Alejo Carpentier es determinante en muchos sentidos. De hecho, el Caribe está presente en toda su obra narrativa, unas veces de modo directo, otras a través de referencias muy concretas e importantes. Puede decirse, en general, que el Mar Caribe o de las Antillas es un referente fundamental de todos sus cuentos y novelas. Por otra parte, también desde un punto de vista teórico ese mar tuvo mucha importancia en el pensamiento de Carpentier. El solo hecho de ser un insular tuvo en él, desde muy joven, un significado muy especial. Tanto dentro del ámbito geográfico, como del histórico y cultural, su Cuba nativa se perfiló en su conciencia como una realidad que no
El Mar Caribe en la vida y la obra de Alejo Carpentier ALEXIS MÁRQUEZ RODRÍGUEZ 


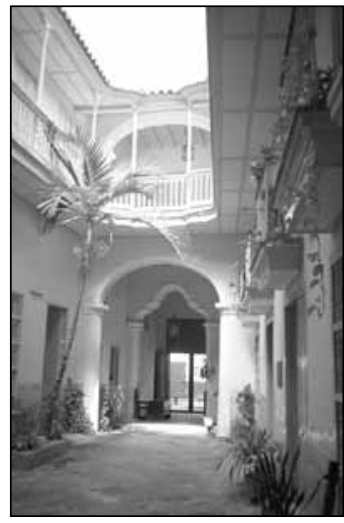

Fundación Alejo Carpentier. Lo Habana. Fotografía de José Gomariz.

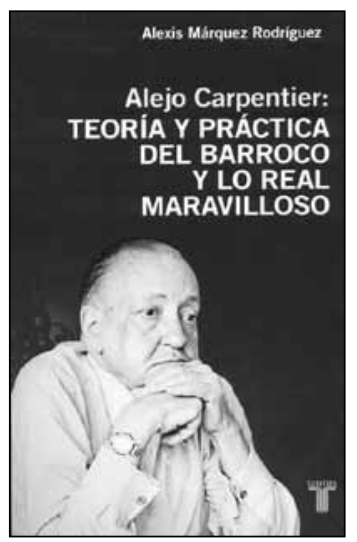

El Mar Caribe en la vida y la obra de Alejo Carpentier ALEXIS MÁRQUEZ RODRÍGUEZ puede ser entendida ni valorada, si no se la considera en relación inmediata con el Caribe.

En su famosa teoría de los contextos que formuló a partir de una feliz expresión de su amigo Jean Paul Sartre- Carpentier incluye lo que él llama contextos geográficos y contextos de iluminación, los cuales, según él, ejercen poderoso influjo en los narradores de nuestro Continente, y en el caso cubano, sostiene, derivan en buena parte de la insularidad del medio, y aun en ciertos rasgos característicos del Caribe, que, o no se dan en otros mares, o poseen en éste una singular peculiaridad («Problemática de la actual novela hispanoamericana.» En Tientos y diferencias).

Justo es decir que tal criterio de Carpentier, derivado de su propia condición de insular, viene, en su caso, a ser fortalecido de manera particular por otros dos factores. En primer término, uno de tipo general, que es común a las personas que han nacido y se han formado en regiones insulares, quienes suelen poseer rasgos de conducta peculiares, que al parecer derivan, al menos en parte, de tal condición. Estas personas, en efecto, suelen ser andariegos, sienten una especial atracción por los viajes y muestran siempre una gran curiosidad ante lo desconocido y una gran ansia de conocer nuevos lugares. Sin embargo, paradójicamente son también muy afectivos frente a su tierra y sus gentes, a los que acostumbran amar con apasionado vigor.

No se vea en estas observaciones concesión alguna a obsoletas teorías deterministas. La afición de los insulares por los viajes tiene, sin duda, un trasfondo psíquico explicable, pues se trata de seres obviamente dispuestos para la navegación, la cual practican primero como actividad económica, como necesidad vital, no sólo de comunicación, sino también de subsistencia, pues del mar extraen lo fundamental de su alimento. Pero tal actividad económica genera predisposiciones afectivas, y crea hábitos viajeros que van más allá de lo económico. Y en cuanto al paradójico apego afectivo a la tierra, su explicación sicológica puede hacerse también desde rigurosos puntos de vista científicos, que no está en nuestro interés analizar aquí.

Junto a estos rasgos psíquicos, que en efecto eran muy notorios en Alejo Carpentier, se daba en su caso otro factor, de enorme importancia. Nos referimos a su compleja y profunda formación cultural, que le permitió valorar en su exacto sentido, no solo el hecho, después de todo fortuito, de haber nacido en una isla, y de haber adquirido en ella su formación inicial, sino también la mucha importancia y la honda significación histórica de aquel Mar Caribe a que su isla pertenece.

\section{II}

Desde muy temprano el joven Carpentier supo establecer los paralelos existentes entre ese mar suyo, tropical, crisol de complejos y fascinantes mestizajes, y, por si fuera poco, escenario de hechos históricos de formidable trascendencia, y otros mares que, del mismo modo, desempeñaron en el pasado un rol histórico y antropológico de decisiva importancia. El tuvo, pues, una doble condición, determinante en su persona de una peculiar sensibilidad, que le permitió comprender y valorar su doble carácter de insular y de hombre del Caribe. Y todo ello se expresó en su obra literaria.

Ya en su primera novela, Ecue-Yamba$O$, escrita en 1927, mientras estaba preso en la cárcel de La Habana, bajo la dictadura de Gerardo Machado, aunque publicada en 1933, Carpentier se refiere al mar en términos que avalan cuanto hasta aquí hemos dicho. La presencia del mar en esta novela primigenia no es, como solía ocurrir respecto de la naturaleza en las novelas hispanoamericanas de aquel tiempo $-\mathrm{y}$ en general en la literatura del Continente-, apenas paisajística o contemplativa. Aquí el mar penetra en el corpus novelesco por la vía del huracán, pero en lugar de ser un elemento ambiental de mayor o menor importancia, adopta más bien un valor temático, en alguna medida determinante de ciertos comportamientos humanos sin duda definitorios.

El huracán no puede verse en esta novela sólo como un hecho episódico. En la historia de los pueblos del Caribe los huracanes han tenido una tremenda importancia. La palabra huracán, de origen al parecer taíno o caribe, no sólo designa un fenómeno natural, sino que, además, se supone relacionada con fuerzas esotéricas, con deidades primitivas e incluso demoníacas (Es curioso, por cierto, que en Ecue-Yamba-O Carpentier no emplea la palabra huracán ni una sola vez, sino los vocablos temporal y ciclón. Lo apuntamos sólo como un dato circunstancial, porque lo que interesa en este caso no es la palabra empleada, sino la presencia del fenómeno en el texto narrativo). 
Dentro de la secuencia argumental de la novela el episodio del temporal juega un papel muy importante, que trasciende de lo anecdótico a lo temático. Pero, desde otro punto de vista, da oportunidad al joven novelista para escribir una de sus más hermosas páginas, en la que ya apuntaban con firmes trazos los rasgos fundamentales del estilo carpenteriano, que más tarde, a partir del cuento «Viaje a la semilla» (1944) y de la novela El reino de este mundo (1949), va a mostrar su espléndida madurez.

Aquel pasaje de Ecue-Yamba-O, no obstante su lejanía en el tiempo y pese al valor bastante secundario de la novela, es de los destinados a perdurar como preciosa muestra de la escritura de un autor cuyo valor esencial se resume, precisamente, en un estilo personalísimo, pero llamado a abrir caminos y a marcar de manera profunda varias generaciones de narradores posteriores a él. No podemos sustraernos a la tentación de mostrar aquí tal magnificencia estilística, a través de unos fragmentos del pasaje señalado:

La fricción de vientos contrarios se produjo sobre un gran viñedo de sargazos, donde pececillos de cristal, tirados por un elástico, saltaban de ola en ola. Punto. Anillo. Lente. Disco. Cráter. Orbita. Espiral de aire en rotación infinita. Del zafiro al gris, del gris al plomo, del plomo a la sombra opaca. Los peces se desbandaron hacia las rondas submarinas, en cuyas ramas se mecen cadáveres de bergantines. Los hipocampos galoparon verticalmente, levantando nubes de burbujas con sus casquillos de escamas. El serrucho y la espada forzaron la barrera de las bajas presiones. Vientres blancos de tintoreras y cazones, revueltos en las oquedades de las rocas. Una estela de esperma señaló la ruta del éxodo. Cilindros palpitantes, discos de luz, elipses con cola, emigraban en la noche de la tormenta, mientras los barcos se desplazaban hacia la izquierda de los mapas. Fuga de áncora y aletas, de hélices y fosforescencias, ante la repentina demencia de la Rosa de los Vientos. Un vasto terror antiguo descendía sobre el océano con un bramido inmenso. Terror de Ulises, del holandés errante, de la carraca y del astrolabio, del corsario y de la bestia presa en el entrepuente. Danza del agua y del aire en la oscuridad incendiada por los relámpagos. Lejana solidaridad del sirocco, del tebbad y del tifón ante el pánico de los barómetros. Colear de la gran serpiente de plumas arrastrando trombas de algas y de ámbares. Las olas se rompieron contra el cielo y la noche se llenó de sal. Viraje constante que prepara el próximo latigazo. Círculo en progresión vertiginosa. Ronda asoladora, ronda de arietes, ronda de bólidos transparentes bajo el llanto de las estrellas enlutadas. Zumbido de élitros imposibles. Ronda. Ronda que ulula, derriba e inunda. A terremoto del mar, temblor de firmamento. Santa Bárbara y sus diez mil caballos con cascos de bronce galopan sobre un rosario de islas des-

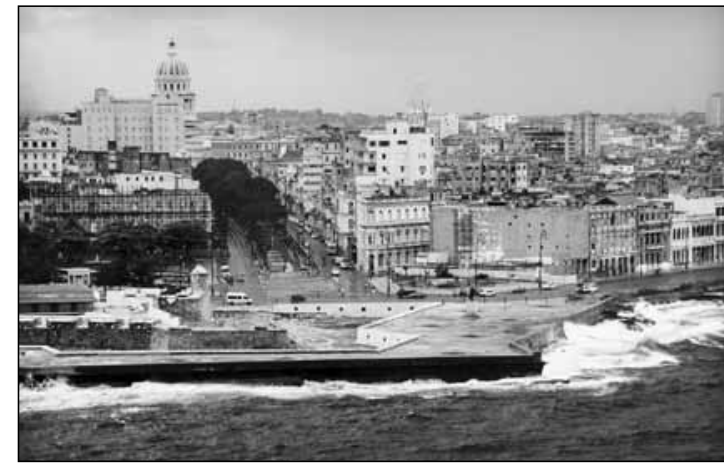

El Prado desde el Morro. La Habana, Cuba. Fotografía de Liset Cruz. amparadas. (...) Ya los ríos acarrean reses muertas. EI mar avanza por las calles de la ciudad. Las viviendas se rajan como troncos al fuego. Los árboles extranjeros caen, uno tras otro, mientras las ceibas y los júcaros resisten a pie firme. Las vigas de un futuro rascacielos se torcieron como alambre de florista. CIGARROS, se lee todavía en un anuncio lumínico, huérfano del fluido, cuyas letras echarán a COLON, responde otro rótulo en el lado opuesto de la plaza martirizada. El ataúd de un niño navega por la calle de las Animas.

Encajándose en el tronco de una palma, un trozo de riel ha dibujado una cruz. La prostituta polaca, olvidada en un barco-prisión, empieza a reír. CI A ROS. Las letras que caen cortan el asfalto como hachazos. Rotas sus amarras, los buques comienzan a reñir en el puerto a golpes de espolón y de quilla. Las goletas de pesca viajan por racimos, llevando marineros ahogados en sus cordajes entremezclados. Las olas hacen bailar cadáveres encogidos como fetos gigantes. Hay ojos vidriosos que emergen por un segundo; bocas que quisieran gritar, presintiendo ya las horrendas tenazas del cangrejal. Cada mástil vencido pone un estampido en la sinfonía del meteoro. La virgen del gran campanario se desploma con fragor de explosión subterránea. Su cabeza coronada rueda, Reina abajo, como un lingote de plomo. CI... C . LON, dicen todavía los rótulos. CI... C . LO, dirán ahora. Mil toneles huyen a lo largo de un muelle, bajo los empellones del alud que gira. La torre de un ingenio se quiebra como porcelana, despidiendo astillas de cemento. Las ranas de una charca ascienden por la columna de agua que aspira una boca monstruosa. (Caerán, tres días más tarde, en el corazón del Gulf Stream). Cielo en ruinas. Está constelado de estacas, timones, plumas, banderas y tanques de hierro rojo. Un carro de pompas fúnebres vaga sin rumbo, guiado por tres ángeles heridos... En la plaza sólo ha quedado el ojo vacío de una $\mathrm{O}$, porque dejó pasar el viento por el hueco de su órbita.

Temporal, temporal

¡Qué tremendo temporal! 
El ciclón ha pasado, ensangrentando aves y dejando un balandro anclado en el techo de una catedral. $(56-57)$

Este pasaje de Ecue-Yamba-O es, además, muy importante, no sólo por su valor estilístico, sino también porque refleja una temprana madurez en Carpentier en lo tocante a su concepto del Caribe desde un triple punto de vista estético, histórico y antropológico. Al margen de la calidad estética del texto, en que con gran acierto se equilibran lo descriptivo y lo narrativo a través de un lenguaje de evidentes tonalidades barrocas, es digna de observar la relación que el autor establece entre el huracán del Caribe y las tormentas características de otras regiones, el tebbad, el sirocco y el tifón, de tan antigua fama de terror, motivos de viejas historias y de ancestrales leyendas, con una remota prosapia literaria, que en la novela moderna se resume con toda brillantez en la obra de Joseph Conrad. Conrad es, por cierto, uno de los pocos escritores de quienes Carpentier confesaba sentirse en alguna medida tributario (Márquez Rodríguez 166-169).

Destaca igualmente en el texto citado la relación que Carpentier señala entre el huracán caribeño, que siembra el terror entre los pobladores de las islas y de las zonas ribereñas de la tierra firme, y el terror que las tempestades siempre han generado en los hombres del mar. Terror de Ulises ante los fragores del mar en su periplo por el Mediterráneo. Terror del Holandés Errante, en su navegar sin término por todos los mares del mundo. Terror de los marinos que llevaron la carraca, el astrolabio y la piratería a latitudes mucho más allá de las que se reputaban los confines del mundo, la última Thule o las Islas Afortunadas. ¡Los grandes mitos del mar, redivivos en el ámbito prodigioso del Caribe! Carpentier estaba consciente de ello. El Mar Caribe, y sobre todo la periódica y alucinante fuerza destructiva de sus huracanes, entraban por derecho propio en la cantera de los grandes mitos universales. Tal conciencia no se muestra sólo en pasajes de sus novelas, sino también en muchos de sus escritos no estrictamente imaginativos o literarios. En un artículo publicado en el diario El Nacional, de Caracas, dentro de su columna «Letra y solfa», el 22 de septiembre de 1953, Carpentier decía lo siguiente:

Los españoles, maravillados de lo que ellos mismos habían descubierto, hicieron mitos de todo: de la
Piedra Bezar, hallada en las entrañas del venado americano; de las Amazonas, del Dorado, del Potosí, del Valle de Jauja; algunos vieron a los caimanes como «espantables (sic) dragones», en tanto que otros buscaron la Fuente de la Eterna Juventud. El ciclón antillano habría de merecer también los honores de una mitología.

Y que no se trataba de meros hechos imaginativos o fantasiosos, especulaciones de novelista invencionero y fabulador, lo demuestra otro artículo de la misma serie, publicado el 2 de octubre de 1952. En éste se da cuenta del carácter periódico de los huracanes, que suelen azotar a Cuba y otras islas antillanas en los meses de septiembre y octubre, y se hace especial referencia al de 1927, de inusitada intensidad, y que sin duda sirvió de referente al pasaje de Ecue-Yamba-O que antes transcribimos, novela, como se sabe, escrita ese mismo año, cuando la impresión del espantoso huracán estaba todavía viva en los cubanos. En dicho artículo dice el autor:

Ese desencadenamiento de ciclones, cada otoño, en el Caribe, es todavía una presencia, siempre activa de las pavorosas "tormentas de las Bermudas», citadas por Shakespeare y los dramaturgos del Siglo de Oro español -tormentas que llegaron a hacerse mitos americanos, desde los inicios de la Conquista, como la existencia de las Amazonas o la Fuente de la Eterna Juventud. [...]

La Habana acepta, como algo normal, la fatalidad de un ciclón que, cada diez años - en promedio - habrá de caer sobre la ciudad, causando los consiguientes estragos. El correspondiente al año 1927 - el anterior se había arrojado de lleno sobre la capital en 1917dejó una serie de fantasías tremebundas, como marcas de su paso: una casa de campo trasladada, intacta, a varios kilómetros de sus cimientos; goletas sacadas del agua, y dejadas en la esquina de una calle; estatuas de granito, decapitadas de un tajo; coches mortuorios, paseados por el viento a lo largo de plazas y avenidas, como guiados por cocheros fantasmas. y, para colmo, un riel arrancado de una carrilera, levantado en peso, y lanzado sobre el tronco de una palma real con tal violencia, que quedó encajado en la madera, como los brazos de una cruz.

En otra de sus novelas, El Siglo de las Luces (1962), tenida en general por cumbre de su obra, el tema del huracán vuelve a presentarse y es de nuevo tratado con particular interés y con un aún más maduro desarrollo literario, dentro de aquella concepción del 
peculiar fenómeno como algo más que un episodio novelesco. En la trama de esta novela la escena del ciclón adquiere una importancia fundamental. Tanto, que dicha escena sirve de hito en la secuencia argumental. A partir de ella los hechos cambian de rumbo. De manera muy significativa es ese el punto que marca el inicio del periplo revolucionario de Esteban, pues la huida de La Habana que emprende a raíz del ciclón, aprovechando el aplazamiento momentáneo que este ha impuesto a las autoridades en su propósito de hacer una redada de francmasones y conspiradores, es el primer paso del viaje que lo lleva, junto con Víctor Hugues, primero a Santo Domingo, y luego a Francia, donde otro huracán, pero de distinto signo, ha derribado la monarquía y hecho rodar las cabezas de los reyes y de centenares de hombres y mujeres más, barridos por los vientos ciclónicos de la Revolución.

Mas aquel temporal habanero también significó en Sofía - el otro personaje clave de la novela - un sacudimiento trascendental. A raíz de la escena del ciclón, esa misma noche, con el propio ciclón como contexto, Víctor Hugues trata de seducir a la joven, en circunstancias y condiciones que moralmente casi configuran un intento de violación.

Para Sofía aquel episodio posee numerosas implicaciones. Lo esencial es que, por primera vez, se siente deseada, y adquiere con ese sentimiento lo que el autor define como «la conciencia de sí misma» (247). En todo caso, fue un sacudimiento psicológico, una especie de huracán anímico que, también en ella, marcó un punto crucial en su vida y torció el rumbo de su existencia.

\section{III}

Pero el Caribe no es, para Carpentier, sólo el huracán. También en El Siglo de las Luces, con bastante precisión y abundancia de datos se nos da el exacto valor que aquel mar tenía para el novelista cubano. Esteban, devenido de pronto en contable de corsarios, vive durante meses una singular experiencia marinera, en la cual lo más resaltante y prodigioso es el descubrimiento de aquel mar que ha sido el de toda su vida, pero que ahora, en la madurez de su conciencia y de su sensibilidad, y en contacto directo e íntimo con su realidad natural y cultural, no vista ya desde la perspectiva de la tierra, sino desde el frágil pi-

so de una embarcación deleznable y precaria, se le revela en toda su plenitud.

Además, Esteban venía de una adolescencia que vivió recluido entre los muros de su casa, aquejado por el asma, lo que le había impedido tener más temprano aquella visión del Caribe,

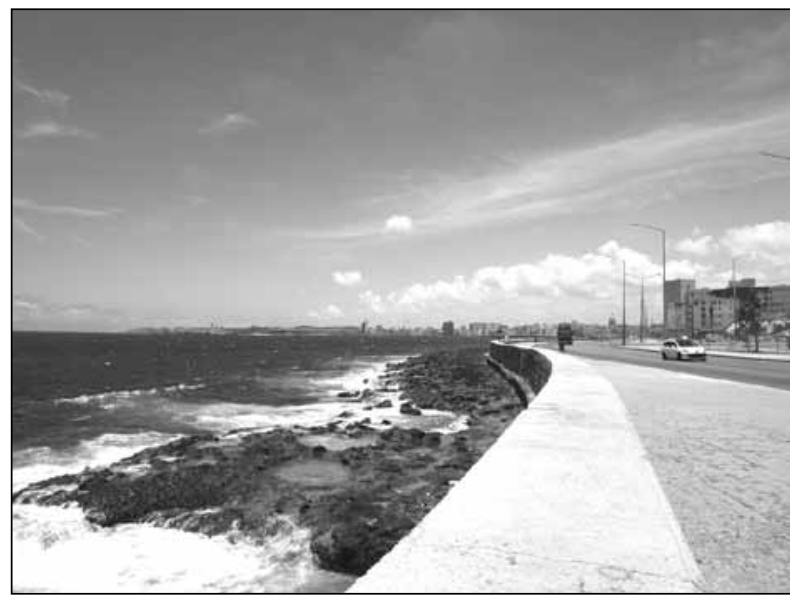

EL Malecón. La Habana, Cuba. Fotografía de Paul Niell. tan cercano, sin embargo, y tan entrañable, y que apenas ahora empezaba a conocer de verdad.

Por una parte es la realidad paisajística, muestra preciosa de lo real maravilloso en su dimensión natural, que a su vez se vincula con ese otro fenómeno, consustanciado con la esencia natural y cultural de nuestro Continente, que es el barroco americano. Carpentier ha sostenido con vehemencia que el barroco es el estilo propio del mundo americano, no sólo porque es la expresión cabal de un mestizaje de triple raíz barroca - la indígena, la africana y la española-; sino también porque es ya la propia naturaleza que nos rodea la que condiciona nuestro lenguaje, nuestras diversas formas de expresión, nuestras costumbres y, en general, nuestra especificidad idiosincrásica, en un sentido necesariamente barroco.

Para él, una tan peculiar naturaleza barroca americana no podía ser captada, ni expresarse cabalmente, sino a partir de una sensibilidad barroca, y a través de un estilo barroco. Y dentro de esa naturaleza americana, cuajada de barroquismos presentes y de «barroquismos por venir,» el Caribe adquiere una especial dimensión. Basta leer aunque sea fragmentos de los magistrales cuadros descriptivos de El Siglo de las Luces en que se pinta el escenario caribeño, para que se nos revele tal dimensión barroca:

Eran vivas pencas de madréporas, la poma moteada y cantarina de las porcelanas, la esbeltez catedralicia de ciertos caracoles que, por sus piñones y agujas, sólo podían verse como creaciones góticas; el encrespamiento rocalloso de los abrojines, la pitagórica espiral del huso -el fingimiento de muchas conchas que, ba-

El Mar Caribe en la vida y la obra de Alejo Carpentier ALEXIS MÁRQUEZ RODRÍGUEZ 


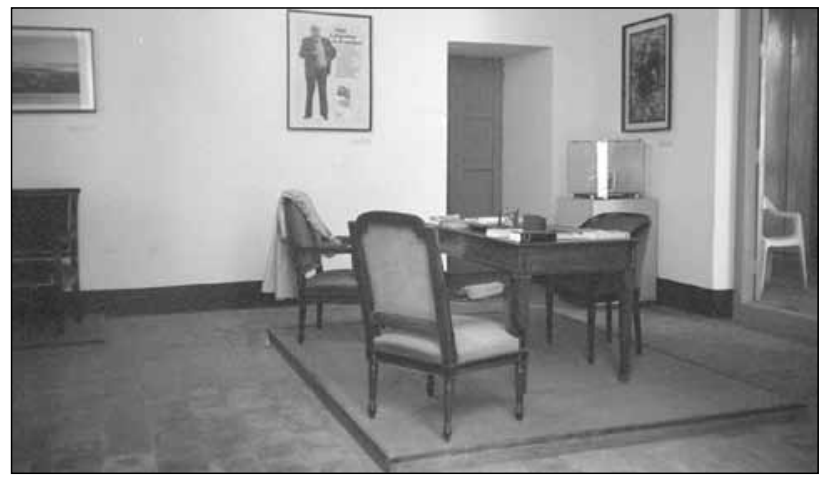

Mobiliario del despacho de Alejo Carpentier en la Embajada de Cuba en París. La Habana. Fotografía de José Gomariz. jo la yesosa y pobre apariencia, ocultaban en las honduras una iluminación del palacio engualdado. (...) En ese prodigioso Mar de las Islas, hasta los guijarros del Océano tenían estilo y duende; los había tan perfectamente redondos que parecían pulidos en tomos de lapidarios; otros eran abstractos en forma, pero danzantes en anhelo, levitados, espigados, asaeteados, por una suerte de impulso brotado de la materia misma. (...) Los más portentosos cactos montaban la guardia en los flancos de esas Hespérides sin nombres a donde arribaban las naves en su venturosa derrota; altos candelabros, panoplias de verdes yelmos, colas de faisanes verdes, verdes sables, motas verdes, sandías hostiles, membrillos rastreros, de púas ocultas bajo mentidas tersuras - mundo desconfiado, listo a lastimar, pero desgarrado siempre por el parto de una flor roja o amarilla, ofrecida al hombre, tras la hincada con el alevoso regalo del higo de Indias y de la tuna, a cuya pulpa se accedía por fin a condición de burlar una nueva barrera de cerdas ardientes. (...) La selva de coral hacía perdurar, en medio de una creciente economía de las formas zoológicas, los primeros barroquismos de la creación, sus primeros lujos y despilfarros; sus tesoros ocultos donde el hombre, para verlos, tendría que remedar el pez que hubiese sido antes de ser esculpido por una matriz, añorando las branquias y la cola que hubieran podido hacerle elegir aquellos paisajes fastuosos por perenne morada. (...) Sobre la madera sumergida de los mangles aparecía, de pronto, un blanco espolvoreo de harinas. Y las harinas se hacían hojuelas de pergamino, y el pergamino se hinchaba $y$ endurecía, transformándose en escamas adheridas al palo por una ventosa, hasta que una buena mañana, definíanse las ostras sobre el árbol, vistiéndolo de conchas grises. (...) Ningún símbolo se ajustaba mejor a la Idea de Mar que el de las anfibias hembras de los mitos antiguos, cuyas carnes más suaves se ofrecían a la mano del hombre en la rosada oquedad de los lambíes, tañidos desde siglos por los remeros del Archipiélago, de boca pegada a la concha, para arrancarles una bronca sonoridad de trompa, bramido de toro neptuniano, de bestia solar sobre la inmensidad de lo entregado al sol. (...) Alguna vez se hacía un gran silencio sobre las aguas, presentíase el Acontecimiento y aparecía, enorme, tardo, desusado, un pez de otras épocas, de cara mal ubicada en un extremo de la masa, encerrado en un eterno miedo a su propia lentitud, con el pellejo cubierto de vegetaciones y parásitos, como casco sin carenar, que sacaba el vasto lomo en un hervor de rémoras, con solemnidad de galeón rescatado, de patriarca abisal, de Leviatán traído a la luz, largando espuma a mares en una salida a flote que acaso fuera la segunda desde que el astrolabio llegara a estos parajes. Abría el monstruo sus ojillos de paquidermo, y, al saber que cerca le bogaba un desclavado cayuco sardinero, se hundía nuevamente, a esperar otro siglo para regresar a un mundo colmado de peligros. Terminado el Acontecimiento, volvía el mar a sus quehaceres. Encallaban los hipocampos en las arenas cubiertas de erizos vaciados, despojados de sus púas, que al secarse se transformaban en pomas geométricas de una tan admirable ordenación que hubiesen podido inscribirse en alguna Melancolía de Durero; encendíanse las luminarias del pez-loro, en tanto que el pez-ángel y el pez-diablo, el pez-gallo y el pez-de-San-pedro, sumaban sus entidades de auto sacramental al Gran Teatro de la universal Devoción, donde todos eran comidos, consustanciados, imbricados de antemano, dentro de la unicidad de lo fluido. (150-54)

De modo, pues, que el Caribe viene a ser pieza fundamental de la famosa teoría carpenteriana de lo real maravilloso, adminiculada ésta, a su vez, a su no menos importante teoría del barroco como la genuina expresión americana. Esto, que puede verse en aquellos deslumbrantes cuadros descriptivos como el que acabamos de citar, se hace aún más directo cuando, también en la novela, Carpentier nos da la visión directa del Caribe desde los ojos de Esteban. Que son, en este caso, sin la menor duda, los ojos del propio Carpentier. En otra ocasión hemos señalado cuánto hay de éste en la personalidad de Esteban. Son muchos los rasgos que los hermanan $\mathrm{y}$, a veces, los identifican. Uno de ellos es la especialísima sensibilidad para aprehender ciertas realidades, tal como ocurre, pongamos por caso, ante el mar. Es evidente que, al referirse a este, como en muchas otras ocasiones, Carpentier mira por los ojos y habla por la lengua de Esteban. Como en el siguiente pasaje, en que al describir el novelista el paisaje barroco del Caribe tal como lo contemplaban los ojos de Esteban, es su propia visión de ese paisaje lo que describe:

el mundo de las Antillas fascinaba al joven, con su perpetuo tornasol de luces en juego sobre formas diversas, portentosamente diversas, dentro de la unidad de un clima y de una vegetación común. 
Toda una mitología de naufragios, tesoros perdidos, sepulturas sin epitafio, luces engañosas encendidas en noches de tormenta, nacimientos predestinados -el de Madame de Mantainon, el de un taumaturgo sefardita, el de una amazona que llegó a ser reina de Constantinopla - se unía a estas tierras cuyos nombres repetíase Esteban en voz baja, para gozarse de la eufonía de las palabras: Tórtola, Santa Ursula, Virgen Gorda, Anegada, Granadinas, Jerusalem Caída. (165)

Obsérvese que en este texto se vinculan de modo expreso la descripción en alto grado barroca del paisaje caribeño, y la realidad de corte prodigioso, que se trasunta en mitos, leyendas, predestinaciones y maravillosas coincidencias, cantera inagotable, todo ello, de lo real maravilloso americano.

A esta idea del Caribe como punto de confluencia y de simbiosis de lo barroco y lo real maravilloso, indudable señal de identidad de la naturaleza y de la cultura de nuestro Continente, se une también el hecho, de igual signo portentoso, de que el Caribe fue el gran crisol en que se fundieron las raíces primigenias que dieron origen al mestizaje que, a su vez, produjo al hombre de América, con su específica singularidad. Hecho que no puede verse sólo como un fenómeno étnico o antropológico, puesto que fue al mismo tiempo un acontecimiento histórico, cuya trascendencia no siempre ha sido valorada con acierto. Es una mezcla si se quiere prodigiosa de etnias dispersas, pero también distintas, que de pronto se encuentran. Mezcla que no se queda en lo sanguíneo, sino que abarca así mismo lo cultural.

Pero hay algo más. Ese encuentro de razas y culturas que se realiza en el Caribe es, al mismo tiempo, el punto culminante de un proceso de integración universal, que venía gestándose desde los más remotos tiempos. Simbólicamente, piensa Carpentier, esa convergencia integradora puede resumirse en la gran metáfora histórica que representa el encuentro del Mediterráneo y el Caribe, dos mares que parecieran llamados a un destino común, como centros de fusión y de amalgama de los pueblos dispersos sobre la faz de la tierra. Y es de nuevo Esteban, es decir, el propio Carpentier desdoblado en personaje de sí mismo, quien intuye el formidable acontecimiento:

En Francia había aprendido Esteban a gustar el gran zumo solariego que por los pezones de sus vides había alimentado la turbulenta y soberbia civilización mediterránea -ahora prolongada en este Mediterráneo Caribe, donde proseguíase la Confusión de Rasgos iniciada, hacía muchísimos milenios, en el ámbito de los Pueblos del Mar. Aquí venían a encontrarse, al cabo de larga dispersión, mezclando acentos y cabelleras, entregados a renovadores mestizajes, los vástagos de las Tribus Extraviadas, mezclados, entremezclados, despintados y vueltos a pintar, aclarados un día para anochecerse en un salto atrás, con una interminable proliferación de perfiles nuevos, de inflexiones y proporciones, alcanzados a su vez por el vino que, de las naves fenicias, de los almacenes de Gades, de las ánforas de Maarkos Sestios, habían pasado a las carabelas del Descubrimiento, con la vihuela y la tejoleta, para arribar a estas orillas propiciadoras del trascendental encuentro de la Oliva con el Maíz. (157)

Inevitable recordar, ante estas ideas, el pensamiento visionario de Simón Bolívar, no sólo cuando habla de que los latinoamericanos «somos un pequeño género humano," sino también cuando postula el Istmo de Panamá - vale decir, el Mar Caribe - como el centro natural del orbe, el punto de convergencia a donde habrían de mirar todos los pueblos del mundo, en busca de una armonización universal sólo posible mediante el imperio de la paz y del progreso sobre toda la humanidad.

\section{IV}

Que no se trata de una simple especulación literaria, sino de una convicción muy firme y arraigada en el pensamiento carpenteriano, lo demuestra el hecho de que esta misma visión del Caribe que experimenta Esteban reaparece otras veces en la obra de Carpentier, incluso muchos años después de la novela, ya no dentro de un texto propiamente literario, sino en algunos de sus escritos de carácter ensayístico o conceptual. Por ejemplo, en una charla sobre «La cultura de los pueblos que habitan en las tierras del Mar Caribe,» difundida por la Televisión cubana dentro del marco del Festival del Caribe (Carifiesta), celebrado en La Habana el 19 de julio de 1979, expresó lo siguiente:

nuestro suelo, y muy particularmente el suelo caribe, se hace teatro de la primera simbiosis, del primer encuentro registrado en la historia de tres razas que, como tales, no se habían encontrado nunca: la blanca de Europa, la india de América, que era novedad
El Mar Caribe en la vida y la obra de Alejo Carpentier ALEXIS MÁRQUEZ RODRÍGUEZ 

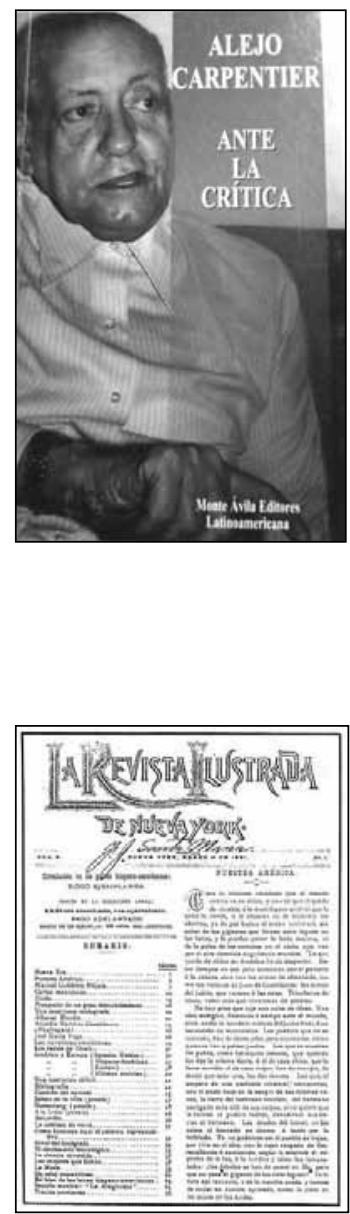

El Mar Caribe en la vida y la obra de Alejo Carpentier ALEXIS MÁRQUEZ RODRÍGUEZ total, y la africana, que, si bien era conocida por Europa, era desconocida totalmente del lado de acá del Atlántico. Por lo tanto, una simbiosis monumental de tres razas de una importancia extraordinaria por su riqueza y su posibilidad de aportaciones culturales y que habría de crear una civilización enteramente original. (En La novela latinoamericana en vísperas de un nuevo siglo 181-82)

Como puede verse, son estas, mutatis $m u$ tandi, las mismas palabras de Esteban, en El Siglo de las Luces, por cuya boca hablaba el propio Carpentier. Aquí ya no recurre a ninguno de sus personajes para expresar su pensamiento, sino que lo formula de un modo directo y expreso.

Hay, pues, un valor y un sentido ecuménico en esta idea del Mar Caribe como un gigantesco crisol de razas y de culturas, que representa al mismo tiempo el gran punto de convergencia en que el Hombre, desperdigado en etnias, culturas y pueblos diversos, vuelve a su esencia universal y se refunde en el principio humanístico de integración y unidad.

Humanismo es, precisamente, el vocablo y el concepto invocados por el propio Carpentier, para resumir con entera propiedad su idea acerca de lo que ha sido, desde el principio, el destino histórico del Mar Caribe, y de las tierras y pueblos que se extienden y han vivido dentro de él y en torno suyo. Es sabido que América ha significado, para muchos de los pensadores que a través de los siglos han sido los mejores exponentes del humanismo europeo, la esperanza de la humanidad, en el sentido de ser la reserva natural donde han de hallar refugio definitivo las ansias de paz, de libertad y de bienestar que, al decir de José Carlos Mariátegui, constituyen el mito primordial que el hombre viene persiguiendo desde sus más remotos orígenes.

De manera expresa Carpentier habló alguna vez de la existencia de lo que él llamaba un humanismo caribe. Esta idea la formuló en la misma charla difundida por la Televisión cubana a que antes hemos hecho referencia:

Los grandes hombres cuyos nombres acabo de citar [Francisco de Miranda, Simón Rodríguez, Simón Bolívar, Brion, Toussaint Louverture, Petion, Heredia, Máximo Gómez, Finlay, José Martí, Fidel Castro] vienen a demostrar que existe lo que podríamos llamar un humanismo caribe. Nuestros grandes hombres nunca limitaron su acción, su pensamiento, su ejem- plo, al ámbito propio, sino que se proyectaron hacia los pueblos vecinos. Hubo intercambio de hombres como hubo interpenetración de ideas. Hubo siempre entre nosotros un entendimiento mutuo dentro de las aspiraciones que nos eran comunes... (187-88)

Esta afirmación de Carpentier, que expresa su sentimiento internacionalista y de integración de los pueblos, más allá de los regionalismos y localismos patrioteros y de un nacionalismo antidialéctico y pseudorevolucionario, sentimiento internacionalista que a su entender es meollo del humanismo, alude a un hecho siempre presente en la historia americana, como es el sentimiento y la idea de solidaridad, y aún de fraternidad, que ha sido uno de los rasgos espirituales típicos del hombre y de los pueblos de América. Es obvio que no puede verse nuestro Continente como una unidad monolítica, tal como de manera equivocada - concediéndoles el beneficio de la buena fe - lo ha pretendido cierta corriente de pensadores europeos y estadounidenses, empeñados en entender en forma mecánica nuestra realidad continental como un todo más o menos confuso, identificable por algunos rasgos como el pintoresquismo, el exotismo y el subdesarrollo, entre otros.

La tendencia a presentar tales características, en apariencia definitorias de lo americano, como signos positivos, capaces de despertar el interés y la admiración del europeo y del estadounidense supercultos y superdesarrollados, como suele verse en los carteles de publicidad turística, disimula mal el trasfondo de desprecio y, hasta cierto punto, de conmiseración que alienta en lo profundo de tal tendencia. Alejo Carpentier ha sido uno, por cierto, de los escritores latinoamericanos que con mayor vehemencia y con mejor fundada argumentación, han rechazado semejante modo de concebir nuestra presunta tipicidad. Para él siempre estuvo muy claro que Nuestra América - como solía llamarla José Martí- es, desde luego, una unidad en muchos aspectos, pero en el seno de la cual existen también importantes diferencias regionales, nacionales y aun locales. Se trata, pues, de una diversidad dentro de la unidad.

Entre los rasgos comunes, entre los elementos que apuntalan ese sentido de unidad, destaca aquella propensión a la solidaridad entre nuestros pueblos, más allá de fronteras geográficas o ideológicas. 
Este fenómeno se puso en evidencia sobre todo durante las guerras de independencia. No sólo es el hecho de que un mismo hombre, el venezolano Simón Bolívar, sea tenido por Libertador y padre de la Patria en seis distintas naciones del Continente; es bien sabido, así mismo, que en las luchas emancipadoras de cada uno de nuestros países participaron hombres provenientes de muchos otros lugares, incluso de Europa. Y fue entre los pueblos del Caribe que este hecho se dio con más frecuencia y con mayor notoriedad. Es conocida la invalorable ayuda que Bolívar recibió de Alejandro Petion, el presidente de Haití. El Almirante Luis Brión, otro de los héroes de la independencia venezolana, era de Curazao. Máximo Gómez, figura prominente de la independencia cubana, había nacido en Santo Domingo. También participaron venezolanos en la emancipación de Cuba, y Francisco Javier Yánez, cubano, a su vez tuvo destacada actuación en la de Venezuela. El propio Bolívar se impuso el deber de llevar la libertad a Colombia, Ecuador, Perú y Bolivia, y abrigó, además, la ambición de concluir su tarea emancipadora libertando a Cuba y Puerto Rico de la dominación hispánica, y sólo un cúmulo de circunstancias adversas se lo impidieron.

La solidaridad y la fraternidad, en fin, entre los pueblos de América, y de modo especial entre los que se agrupan en la cuenca del Caribe, islas y tierra firme por igual, se han manifestado siempre de diversas maneras y en las más variadas circunstancias. De modo que podría decirse, a la luz de las palabras de Carpentier que acabamos de citar, que en el Caribe, ya desde los tiempos de las guerras que marcan el derrumbe del vasto imperio colonial de España, nace, o al menos se manifiesta de manera real y concreta, por primera vez desde que surge el concepto de nacionalidad, el principio del internacionalismo revolucionario que más tarde, a mediados del siglo XIX, adquirirá entidad doctrinaria entre los fundamentos esenciales del socialismo científico.

\section{V}

Con lo dicho, sin embargo, no se agota el pensamiento carpenteriano en relación con la importancia y el significado históricos del Mar Caribe. Lo que éste representó en el pasado se proyecta, según atinada observación de Carpentier, en la historia contemporánea. Muy a tono con ese valor pretérito, el desarrollo de la vida política y social de los pueblos caribeños ha marcado, también en el presente, importantes hitos históricos, cuya trascendencia no puede medirse sólo en función de lo actual, sino mas bien por la carga de futuro que subyace en muchos de los acontecimientos ya ocurridos o en proceso de desarrollo:

En el siglo XX los países de nuestra América, dotados de una fuerte conciencia nacional, lucharon y luchan contra el imperialismo, aliado de la gran burguesía criolla, por el logro de una independencia total, unida a un anhelo de progreso social. Y esta segunda parte del siglo XX se ha caracterizado y se caracteriza por la intensificación de esa lucha en todo ese ámbito del Caribe, lucha por una independencia total, independencia total ya lograda en Cuba. (187)

Estas palabras, pronunciadas por Carpentier en 1979, como ya se ha visto, no sólo nos revelan una realidad tangible, en cuanto a los movimientos revolucionarios ocurridos en el ámbito del Caribe, cuya máxima concreción la hallamos en el hecho de que en Cuba se haya establecido el primer régimen socialista en suelo americano, sino que también se nos ofrecen con un claro sentido de vaticinio acerca de lo que, para aquel momento, se presentaba, a quien no tuviese claridad ideológica, con un futuro más o menos incierto. Los sucesos de Nicaragua y otros pueblos de Centroamérica ocurridos sobre todo a partir de 1980, año en que, en abril, muere Carpentier, han venido a darle la razón, a justificar su concepción del Caribe como un mar de profunda vocación histórica y revolucionaria, y a poner de manifiesto la aguda inteligencia y la perspicacia del novelista doblado en pensador.

Nada de esto puede sorprendernos. El conocimiento minucioso de la historia de nuestros pueblos le permitía al gran escritor cubano afirmar que «el Caribe ha desempeñado un papel privilegiado, único, en la historia del continente y del mundo» (181), tal como lo sostiene en la charla que venimos glosando. Y aún más, en ese mismo texto afirma, de manera igualmente categórica, que «el verdadero concepto de independencia» (184) tuvo su origen en el Caribe, y concretamente en el Juramento del Bois Caïman, que marcó el comienzo de una de las primeras rebeliones de los negros ocurridas en Haití antes de su independencia definitiva. En efecto, sostiene Carpentier,
El Mar Caribe en la vida y la obra de Alejo Carpentier ALEXIS MÁRQUEZ RODRÍGUEZ 


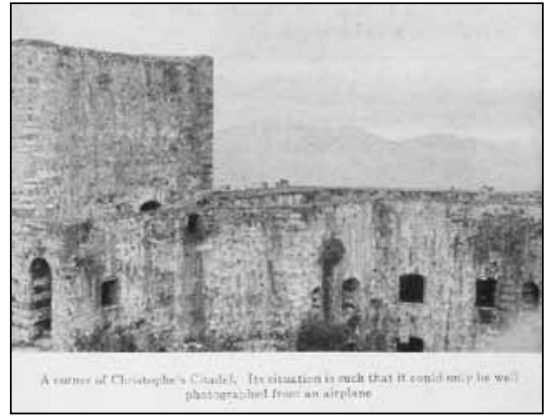

Ciudadela La Ferrière, 1805-1820. Sans Souci, Haití. Schomburg Center for Research in Black Culture. The New York Public Library Digital Collections. 1920.

Me explico: cuando tomamos la gran Enciclopedia, la famosa enciclopedia redactada por Voltaire, Diderot, Rousseau, D' Alembert, a mediados del siglo XVIII en Francia, $\mathrm{y}$ cuyas ideas tanta influencia tuvieron sobre los caudillos de nuestras guerras de independencia, nos encontramos que, en esta gran enciclopedia, el concepto de independencia tiene un valor meramente filosófico. Se dice independencia, sí, independencia del hombre frente al concepto de Dios, frente al concepto de monarquía, el libre albedrío, hasta qué punto llega la libertad individual del hombre, pero no se habla de independencia política. En cambio, lo que reclamaban los negros de Haití - precursores en eso de nuestras guerras de independencia - era la independencia política, la emancipación total.

Yo sé que a esto surge una objeción fácil. Muchos se dirán: ¡Un momento, el Juramento del Bois Caïman tiene lugar en 1791, pero ya mucho antes había habido la independencia de los Estados Unidos! ¡Pero quién lo niega! No hay que olvidar (no obstante) que cuando las trece colonias norteamericanas se emancipan de la autoridad del rey de Inglaterra y pasan a ser un país independiente que ya no es tributario de la Corona británica, no ha habido un cambio de estructuras en la vida de esas colonias: los terratenientes siguieron siendo los mismos terratenientes; los grandes propietarios, los grandes comerciantes siguieron viviendo exactamente como antes. A nadie le entró en la cabeza que pudiera haber una emancipación de esclavos. Para llegar a esa emancipación habrá que esperar a la Guerra de Secesión. Es decir, que en los Estados Unidos se siguió como antes después de la proclamación de la independencia, después de Jefferson, después de Jorge Washington. (184-85)

Y al final concluye:

¡Ah, pero en la América Latina no ocurrió lo mismo! Porque a partir de las revueltas de Haití, que fueron seguidas muy poco después por la serie de guerras de independencia que lograrían su victoria final en 1824, en la victoria de la batalla de Ayacucho, las estructuras de la vida, las estructuras sociales, variaban de una manera total, y variaban de una manera total por la aparición en el primer lugar del escenario histórico de un personaje que políticamente no había sido tomado en cuenta, si bien humanamente existía. Y ese personaje es el criollo. (185)

Como se ve, pues, las ideas de Carpentier

El Mar Caribe en la vida y la obra de Alejo Carpentier ALEXIS MÁRQUEZ RODRÍGUEZ acerca del Caribe no son meros pensamientos más o menos aislados, ni atisbos más o menos sagaces, ni menos aún explosiones patrioteras o regionalistas. Antes bien, constituyen una concepción global, orgánica, coherente, fundamentada en el conocimiento circunstanciado de nuestra historia, y en el análisis dialéctico de ésta, realizado, por lo demás, con una diáfana inteligencia y sin hacer concesiones a ningún tipo de dogmatismo ni de retórica ideológica.

Esa idea doctrinaria del Caribe concebida por Alejo Carpentier es parte, por lo demás, de su concepción doctrinaria de América. Su concepto del Caribe como un mar histórico; su idea de éste como un prodigioso crisol de razas y culturas y como punto de convergencia de los pueblos dispersos por todo el orbe; su firme convicción de que ese mar ha desempeñado, y ha de seguir desempeñándolo, un rol fundamental en la historia de la humanidad; todo ello debemos verlo en directa y dinámica concordancia con otros conceptos suyos de valor capital, como la definición de América en tanto que continente de lo real maravilloso, y la postulación del Barroco como la auténtica y específica forma de expresión latinoamericana y caribeña. Son ideas que integran un totus ideologicus, orgánico, coherente, que lo mismo se pone de manifiesto en su espléndida obra narrativa, como en la fecunda madurez de sus escritos periodísticos y ensayísticos.

\section{Bibliografía}

Carpentier, Alejo. El Siglo de las Luces. México: Compañía General de Ediciones, 1962.

- Tientos y diferencias. Montevideo: Arca, 1967.

- Ecue-Yamba-O. 1927-1933. Madrid: Alfaguara, 1982.

- «La cultura de los pueblos que habitan en las tierras del Mar Caribe.» La novela latinoamericana en vísperas de un nuevo siglo $y$ otros ensayos. Madrid: Siglo Veintiuno, 1981. 177-89.

Carpentier, Alejo. Márquez Rodríguez, Alexis: «Nueve preguntas a Alejo Carpentier.» Diario El Nacional. Caracas, 9 de febrero de 1969. En Alejo Carpentier, Entrevistas. La Habana: Letras Cubanas, 1985. 166-169.

Fecha de recepción: 06/05/2014

Fecha de aceptación: 07/10/2014 